\title{
4. Exploring new frontiers to generate an integrated definition of workaholism
}

\author{
Lynley H.W. McMillan and \\ Michael P. O'Driscoll
}

Workaholism is generally understood to involve an unwillingness to disengage from work. Workaholics' most notable characteristics are tendencies to:

(a) work with a passion that is obvious to the outside observer

(b) think about work four times more frequently, compared to nonworkaholics, after most other people have mentally 'switched off'

(c) focus their conversation on work, even in social situations

(d) strive for tangible achievenents in the workplace

(e) work slightly more hours than others.

(McMillan et al., 2004)

In general, contemporary data indicate that workaholism represents a value system about the importance of working and achieving that certainly does not meet the scientific criteria for addiction, as it is associated with a similar quality of health and relationships to that of the rest of the adult population, and generally does not worsen over time (McMillan and O'Driscoll, 2004). Interestingly, while the majority of workaholics appear to derive high enjoyment from their work and their leisure, it is their reluctance to utilize psychological 'off-buttons' that potentially makes them a challenging group for management professionals (Machlowitz, 1980).

In order to address some of these issues, this chapter comprises four major sections: (a) philosophical and epistemological frameworks underpinning current research, (b) a review of contemporary definitions, (c) illustrative data from an inductive/qualitatitive study, and (d) conclusions and a preliminary conceptual model based on an integration of the deductive and inductive data. Given that the extant body of knowledge is largely based in positivist research designs, the alternate framework for generating 
a definition of workaholism is based on triangulated data sources (from workers, their colleagues and their partners). The initial section therefore provides an overview of the philosophical and epistemological frameworks of current research, which generates a précis of the range of design parameters available to researchers. This will provide a succinct orientation for researchers who want to enter, review, or change their research approach in the workaholism domain.

\section{PHILOSOPHICAL AND EPISTEMOLOGICAL FRAMEWORKS}

Workaholism research is conducted predominantly from within a social science paradigm. Social scientists formally define a theory as a system of logical statements that explain the relationship between two or more phenomena (Berg, 1995). For example, workaholism researchers have investigated relationships between workaholism and constructs such as hours worked, health, relationships and work attitudes. Theory is used to (a) develop explanations about reality, (b) provide a means to classify and organize events, and (c) predict future occurrences of events (Berg, 1995). However, whether research designs start or end with theory is a point of ongoing debate among researchers in many of the social sciences. Thus, it is potentially possible to explore workaholism either by espousing a theory and then investigating its implications or by collecting some data and evolving a theory to explain its patterns. The present section therefore expands these two design options (deductive/inductive), in addition to reviewing alternate methodologies (quantitative/qualitative) and data sources (single source/multiple source).

\section{Design Options (Deductive versus Inductive)}

Deductive investigations (that is, theory before research) begin with ideas and then attempt to disprove them through tests of empirical research (refutation). Inductive investigations, in contrast, begin with data, then generate theoretical innovation afterward (that is, research before theory). Deductive research designs begin with theory then move on to gather data (see Figure 4.1), whereas inductive designs follow the inverse pattern, beginning with data and ending with generating a theory.

Whilst these two approaches represent differing underlying philosophies, some authors suggest that the approaches may actually coexist on a continuum (see, for instance, Berg, 1995). Thus, it is possible, at least theoretically, to investigate workaholism by (a) starting with a theory and 


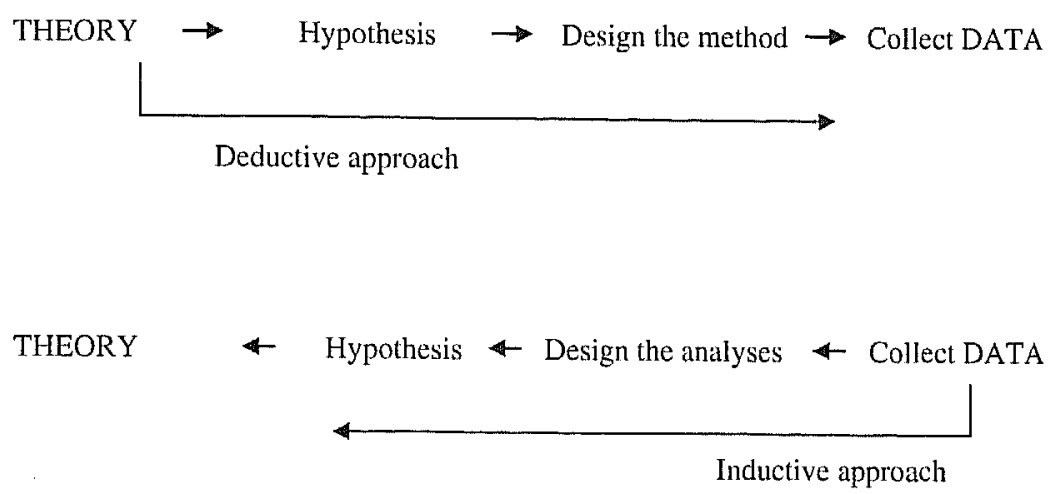

Figure 4.1 Comparison of deductive and inductive models of research

developing hypotheses, research designs and data analysis techniques, or (b) starting by gathering data, allowing them to suggest which analyses are required, then building a theory based on the findings, or (c) utilizing both approaches within the same sample (that is, a composite approach). The benefits of the approaches differ. For instance, theory-first allows researchers to contextualize designs and findings within other scientific disciplines (for example, relate workaholism to both psychological and business theories) and allows for prediction and control of variables. In contrast, a data-first approach could elucidate more diverse trends (such as exceptions to what theory may predict) and may be more sensitive to early changes in behaviour (such as responsiveness of workaholism to evolving mobile technologies). Alternately, a combined approach would allow for both sensitivity and breadth and thus provide a broad range of data on a phenomenon.

However, whilst many fields of psychological enquiry have adopted the composite paradigm (for instance, attitude research), workaholism designs are predominantly deductive. This suggests there is an extraordinary amount of information about workaholism about which we remain unaware. Importantly, if data from the composite approaches converged on the same conclusion, then the present body of knowledge about workaholism could be taken as considerably more reliable, more robust, and perhaps more representative of the phenomenon in question.

Currently, however, because workaholism research has used mostly a theory-down (deductive) approach, it is entirely feasible that how academics view workaholism and how the general public experiences it may be two completely different things. Clearly, if science is committed to thoroughly investigating constructs, we would be prudent to incorporate diverse research epistemologies in exploring the workaholism construct. 


\section{Methodological Options (Quantitative versus Qualitative)}

Methodologically, the social sciences employ two generic ways of gathering data: quantitative and qualitative. Quantity refers to the objective amount of an item. Thus, quantitative research involves counts and measures of things across dimensions, such as frequency, intensity, latency and duration (Berg, 1995). In contrast, quality refers to the subjective essence of an item. Thus qualitative research refers to the meanings, definitions and characteristics of constructs. Clearly, in terms of furthering our understanding about workaholism, we require both quantitative and qualitative information.

In general terms, research data can be generated from two main sources; single-source (self-report) and multiple-source (multidimensional) data. Multidimensional data are typically generated through triangulation. Triangulation is commonly used in surveying, map-making and navigation, where three points are used to draw sighting lines toward an unknown object to estimate its size and characteristics. While two lines could be used, the third line permits a more accurate estimate of the unknown object (Berg, 1995).

Triangulation has been used in the social sciences since 1956 (see Campbell and Fiske, 1959). As outlined in the stress literature, triangulation is considered a desirable design element (Ivancevich and Matteson, 1988). In terms of workaholism research, this would involve informants such as spouses and colleagues (see for instance McMillan and O'D riscoll, 2004). However, the vast majority of data have been single-source, based on self-report, meaning we know little of how people living and working alongside workaholics define, understand and experience the behaviour.

\section{REVIEW OF LAST FOUR DECADES OF PUBLISHED DEFINITIONS}

Given that a wide variety of research designs is available to workaholism researchers, the present section discusses in more detail the definitions of workaholism developed over the last four decades of research.

In general, as outlined in Table 4.1, the majority of definitions of workaholism have been generated deductively and investigated using quantitative frameworks and unidimensional data sources. This trend has largely remained unchanged since the term 'workaholic' came into general usage in 1968. Although Oates's (1968) writing became the basis for much of the later work in the field, his work was rooted in personal conjecture rather than empirical data. 
Table 4.1 Summary of major workaholism definitions, 1968-2004

\begin{tabular}{|c|c|c|c|c|}
\hline Author & Year & Method & Criteria & $\begin{array}{l}\text { Underlying } \\
\text { framework }\end{array}$ \\
\hline Oates & 1968 & $\begin{array}{l}\text { Qualitative } \\
\text { Anecdotal } \\
\text { Introspective } \\
\text { Generically } \\
\text { inductive }\end{array}$ & $\begin{array}{l}\text { 1. Excessive need } \\
\text { for work } \\
\text { 2. Disrupted health, } \\
\text { happiness, } \\
\text { relationships, } \\
\text { social functioning } \\
\text { 3. Withdrawal -- takes } \\
\text { work home } \\
\text { 4. Works outside work } \\
\text { time and conceals it } \\
\text { 5. Starts early and needs } \\
\text { less sleep than others } \\
\text { 6. Works weekends or } \\
2 \text { jobs }\end{array}$ & $\begin{array}{l}\text { Pathological } \\
\text { Addiction } \\
\text { theory }\end{array}$ \\
\hline Machlowitz & 1980 & $\begin{array}{l}\text { Qualitative } \\
\text { Inductive }\end{array}$ & $\begin{array}{l}\text { 1. Intrinsic desire to } \\
\text { work long and hard } \\
\text { 2. Work exceeds others' } \\
\text { expectations } \\
\text { 3. Intense, energetic, } \\
\text { competitive, driven } \\
\text { 4. Strong self-doubts, } \\
\text { needs reassurance } \\
\text { 5. Prefers labour to } \\
\text { leisure } \\
\text { 6. Works anywhere, } \\
\text { any time } \\
\text { 7. Maximizes time usage } \\
\text { 8. Blurs business and } \\
\text { pleasure }\end{array}$ & $\begin{array}{l}\text { Strengths- } \\
\text { based }\end{array}$ \\
\hline Robinson & 1989 & $\begin{array}{l}\text { Quantitative } \\
\text { Deductive } \\
\text { Anecdotal }\end{array}$ & $\begin{array}{l}\text { 1. Overdoing/ } \\
\text { hurrying/binges } \\
\text { 2. Low self-worth/ignore } \\
\text { personal needs } \\
\text { 3. Control/perfectionism } \\
\text { 4. Intimacy difficulties/ } \\
\text { impatience } \\
\text { 5. Mental preoccupation }\end{array}$ & $\begin{array}{l}\text { Pathological } \\
\text { Addiction } \\
\text { theory }\end{array}$ \\
\hline Fassel & 1992 & $\begin{array}{l}\text { Qualitative } \\
\text { Anecdotal } \\
\text { Clinical } \\
\text { interviews }\end{array}$ & $\begin{array}{l}\text { 1. Multiple addictions } \\
\text { 2. Denial } \\
\text { 3. Self-esteem problems } \\
\text { 4. External referencing }\end{array}$ & $\begin{array}{l}\text { Psychological } \\
\text { Addiction } \\
\text { theory }\end{array}$ \\
\hline
\end{tabular}


Table 4.1 (continued)

\begin{tabular}{|c|c|c|c|c|}
\hline Author & Year & Method & Criteria & $\begin{array}{l}\text { Underlying } \\
\text { framework }\end{array}$ \\
\hline & & & $\begin{array}{l}\text { 5. Ability to relax } \\
\text { 6. Obsessiveness }\end{array}$ & \\
\hline $\begin{array}{l}\text { Spence and } \\
\text { Robbins }\end{array}$ & 1992 & $\begin{array}{l}\text { Quantitative } \\
\text { Deductive } \\
\text { Cluster analyses }\end{array}$ & $\begin{array}{l}\text { 1. Work involvement } \\
\text { 2. Drive } \\
\text { 3. Enjoyment }\end{array}$ & $\begin{array}{l}\text { Observable } \\
\text { Behavioural }\end{array}$ \\
\hline Clark et al. & 1993 & $\begin{array}{l}\text { Quantitative } \\
\text { Deductive } \\
\text { Conceptual } \\
\text { sorting }\end{array}$ & $\begin{array}{l}\text { 1. Personality factor }= \\
\text { conscientiousness } \\
\text { 2. Personality trait }= \\
\text { obsessive- } \\
\text { compulsive } \\
\text { 3. Style = perfectionism, } \\
\text { compulsion, energy }\end{array}$ & $\begin{array}{l}\text { Personality } \\
\text { theory } \\
\text { Clinical psycho- } \\
\text { pathology }\end{array}$ \\
\hline Scott et al. & 1997 & $\begin{array}{l}\text { Quantitative } \\
\text { Deductive }\end{array}$ & $\begin{array}{l}\text { 1. Discretionary time } \\
\text { spent working } \\
\text { 2. Thinking about work } \\
\text { when not at work } \\
\text { 3. Working beyond } \\
\text { requirements }\end{array}$ & $\begin{array}{l}\text { Observable } \\
\text { Behavioural }\end{array}$ \\
\hline $\begin{array}{l}\text { McMillan } \\
\text { et al. }\end{array}$ & 2002 & $\begin{array}{l}\text { Quantitative } \\
\text { Deductive } \\
\text { Confirmatory } \\
\text { factor analyses }\end{array}$ & $\begin{array}{l}\text { 1. Reluctance to } \\
\text { disengage from work } \\
\text { 2. Enjoyment } \\
\text { 3. Drive } \\
\text { 4. Work or think } \\
\text { about work } \\
\text { 5. Work any time } \\
\text { or anywhere }\end{array}$ & $\begin{array}{l}\text { Observable } \\
\text { Behavioural }\end{array}$ \\
\hline $\begin{array}{l}\text { Snir and } \\
\text { Harpaz }\end{array}$ & 2004 & Deductive & $\begin{array}{l}\text { 1. Behavioural and } \\
\text { cognitive elements } \\
\text { 2. Steady/stable trait } \\
\text { 3. Not externally } \\
\text { imposed } \\
\text { 4. Not solely attitudes/ } \\
\text { values/beliefs }\end{array}$ & $\begin{array}{l}\text { Observable } \\
\text { Behavioural }\end{array}$ \\
\hline
\end{tabular}

In 1980, Machlowitz published the first empirically based writing on workaholism. Workaholism was conceptualized as a trait that involved an intrinsic desire to work long and hard, led to working beyond job prescriptions, and earned the psychic incomes of responsibility, opportunity and recognition (Machlowitz, 1980). Machlowitz emphasized that workaholics' 
attitudes toward work, rather than the actual number of hours they worked, differentiated them from healthy workers. While the framework involved a partially qualitative design (participants were given open-ended questions and had their responses recorded, coded and analysed), this research prototype appears to have been largely ignored by subsequent workaholism researchers. This is possibly because the results (workaholics reported satisfaction and no more difficulties than other people) contradicted the popular stereotype of the day that workaholics were "miserable slaves'. Machlowitz' work remains one of the few published qualitative studies in the field.

The next influential studies were produced by an American researcher; Bryan Robinson, commencing in 1989. Robinson followed Oates's conceptualization of workaholism and worked primarily from within a family therapy paradigm (Robinson, 1998). Robinson's definition was developed deductively using an addiction paradigm, where the symptoms of addiction were overlaid onto work-specific behaviour. The Robinson definition comprises five aspects: (a) overdoing (hurrying/binges), (b) self-worth (productivity at expense of personal needs), (c) control - perfectionism, (d) intimacy (relationship difficulties/impatience), and (e) mental preoccupation (brownouts/difficulty relaxing). A corresponding measure (the Work Addiction Risk Test: WART) and conceptual models have been developed (Robinson et al., 2001).

Fassel (1992) approached workaholism from an organizational consulting perspective. Based on anecdotal data from organizational clients and Workaholics Anonymous groups, Fassel defined workaholism as comprising six characteristics: (a) multiple addictions, (b) denial, (c) self-esteem problems, (d) external referencing, (e) inability to relax, and (f) obsessiveness. Fassel conceptualized workaholism as following the early-middle-late stage continuum of worsening disease, borrowed from the addiction paradigm. However, while Fassel's work represents an encouraging start at qualitatitive and inductive development of a definition, there was no formal research undertaken, nor systematic descriptions of participants or data analysis. While the ideological approach (qualitatitive/inductive) was of potential utility, the lack of scientific analysis means the definition remains speculative. Additionally, some of the components appear to represent outcomes of workaholism, rather than elements of the construct per se.

Spence and Robbins' (1992) deductively based framework was based on a review of theory and literature that was used to produce a model of workaholism, which was subsequently tested on homogenous samples of students and social workers. Workaholism was defined as a stable trait that involves (a) a high degree of commitment to work, (b) a good deal of time 
spent working, and (c) a compulsion to work even when it is not necessary (Spence and Robbins, 1992). Burke (1999) has subsequently produced a sequence of deductive studies based on the Spence and Robbins' definition.

Clark et al. (1993) used a deductive method based on personality theory and psychometric paradigms to devise and then test a model of Nonadaptive and Adaptive personality. Workaholism was classified as most closely related to the 'big five' personality trait of conscientiousness, fell into the subcategory of obsessive compulsiveness, and involved perfectionism, compulsion and high energy (Clark et al., 1996). However, their conceptualization does not appear to have been utilized specifically by workaholism researchers. Given the robust design methodology, this is somewhat surprising, although the constraints experienced by the present authors in accessing the measure, owing to copyright issues, may provide some explanation. Furthermore, the measure forms part of a larger battery, which may preclude its use in a research-specific context.

Scott et al. (1997) have published perhaps the most rigorous deductive methodology, commencing with an extensive review and critique of the literature, followed by a comprehensive conceptual model, and predicted relationships between variables and resultant research hypotheses. Their analysis suggested a definition that involves three components: (a) discretionary time spent working, (b) thinking about work when not at work, and (c) working beyond requirements. Unfortunately, however, there does not appear to have been any subsequent research that specifically tested their model, and it remains to this day speculative.

At the turn of the century, McMillan et al. (2002) concurrently tested the Spence and Robbins (1992) and the Clark et al. (1996) definitions of workaholism. On the basis of several deductive, data-based studies, McMillan et al. (2004) defined workaholism as comprising five elements: (a) reluctance to disengage from work, (b) enjoyment, (c) drive, (d) work or think about work (e) work any time or anywhere. The important contribution provided by this series of studies is that both the data and measurement sources have been triangulated (see McMillan and O'Driscoll, 2004). Around the same time, Mudrack and Naughton (2001) proposed a behaviourally-based definition of workaholism comprising two elements: (a) non-required work and (b) attempts to control others. This latter criterion (controlling others) is a new concept in workaholism research and still at the preliminary stages of testing. Whilst the Mudrack and Naughton measure has been used in later research (cf. Mudrack, 2004), there does not yet appear to have been any psychometric validation analysis conducted, which means data remain tentative at this stage.

More recently, Snir and Harpaz (2004) suggested that many existing definitions were implicitly value-laden, and argued for the importance of 
researchers to adopt neutral ('non-judgmental') definitions. They proposed that any definition of workaholism should reflect that it is (a) a steady state that involves (b) considerable allocation of time to (c) work-related activities and (d) work-related thoughts (e) that are not derived from external necessity. This definition shares considerable overlap with the McMillan et al. and Scott et al. definitions (see Table 4.1).

Altogether, therefore, the quantitative data on workaholism is predominantly generated from deductive techniques, and, with the exception of McMillan and O'Driscoll (2004), produced from single-source, selfreports. On the other hand, while some encouraging qualitative work has been commenced (for example, Oates, Machlowitz, Fassel) it is largely anecdotal in nature and not tested using scientific frameworks and peer review processes. The following section therefore reviews some preliminary inductively generated data that has been scientifically analysed, in order to compare two definitions, one inductively and one deductively derived.

\section{DATA FROM AN ILLUSTRATIVE INDUCTIVE/ QUALITATIVE STUDY}

The present section reports data from an inductively generated definition of workaholism where participants defined the construct. The epistemological perspective involved applied research in a naturalistic setting, using qualitatitive data from a contrasted group design and data gathered from multivariate sources (that is, triangulated data). The aim was (a) to generate an inductive definition by asking workers, their colleagues and their partners how they would describe someone who was workaholic, then (b) compare their descriptions with a published deductive definition to (c) establish whether the general public concur with the academic definitions of workaholism.

\section{Sample}

The study was conducted in New Zealand in 2001. The sample comprised four groups; workers $(n=55)$, work colleagues $(n=52)$, partners $(n=24)$ and content analysts $(n=9)$.

\section{Workers}

The workers ( 24 male, 31 female) had a mean age of 36.8 years (range $=$ $20-63, S D=11.6$ ). Half of the sample held a tertiary qualification (apprenticeships through to masters degrees), the majority ( 80 per cent) 
were New Zealand European, and most lived in married or de-facto relationships, working in technical, clerical, sales or financial services roles. Workers were categorized into two contrasting groups (workaholic and non-workaholic) using their responses to the Workaholism BatteryRevised (WorkBAT-R: McMillan et al., 2002): a 14-item measure of workaholism comprising two factors, Drive and Enjoyment, that has been previously validated in New Zealand on two separate samples. A detailed description of the classification into groups is provided in McMillan and O'Driscoll (2004). The groups did not differ significantly in terms of gender, age, income or highest qualification. Workaholics had a mean Enjoyment-R score of 5.57 (range $=4.43$ to 6.71 ) and a mean Drive-R of 5.81 (range $=4.86$ to 6.71). Non-workaholics had a mean Enjoyment-R score of 3.62 (range $=1.57$ to 4.43 ) and a mean Drive-R score of 4.05 (range $=2.29$ to 4.83 ).

\section{Colleagues}

Work colleagues of the workaholic group consisted of 12 males and 40 females. While Mann Whitney U tests indicated that none of the following differences were significant, workaholics' colleagues tended to be female $\left(n_{\mathrm{w}}=85\right.$ per cent, $n_{\mathrm{nw}}=69$ per cent), junior $\left(n_{\mathrm{w}}=12\right.$ per cent, $n_{\mathrm{nw}}=27$ per cent $)$ and knew each other for less time $\left(n_{\mathrm{w}}=12\right.$ per cent, $n_{\mathrm{nw}}=46$ per cent) than non-workaholic colleagues. Most colleagues worked in the same department as their corresponding worker $\left(n_{\mathrm{w}}=85\right.$ per cent, $n_{\mathrm{nw}}=81$ per cent).

\section{Partners}

Of the partners, 16 lived with workaholics ( 12 male, 4 female) and 8 with non-workaholics ( 5 male, 3 female). While Mann Whitney $U$ tests indicated that none of the following differences were significant, workaholics' partners tended to be older $\left(M_{\mathrm{w}}=42.4, M_{\mathrm{nw}}=34.5\right)$ and in relationships longer $\left(M_{\mathrm{w}}=13,8, M_{\mathrm{nw}}=11.1\right)$ than non-workaholics' partners.

\section{Content analysts}

The three groups of content analysts ( $\mathrm{n}=3$ members each) comprised nine tertiary qualified people ( 2 male, 7 female), seven of whom were degreequalified psychologists, and two held tertiary qualifications in business studies. Each group had a specific role; the first group simplified the raw data into discrete concepts, the second group conducted a thematic analysis on the simplified raw data to produce clusters of statements, and the third group cross-validated the two sets of data. None had particular expertise in the area of workaholism. 


\section{Measures}

\section{Inductive}

The qualitatitive, written question posed to workers, colleagues and partners was 'How would you describe someone who is workaholic?'

\section{Deductive}

The theoretically derived definition used as a comparison was deductively generated from prior literature reviews, theoretical critiques, and studies conducted on New Zealand working populations (cf. McMillan et al., 2001, 2002, 2003). This particular definition was selected as it had been previously validated on New Zealand samples. The definition was: (a) a personal reluctance to disengage from work, (b) a strong drive to work, (c) intense enjoyment of work, (d) a tendency to work or think about work, and (e) to do this any time and anywhere (McMillan et al., 2004).

\section{Procedure}

\section{Step 1: generating raw data}

Workers, colleagues and partners $(n=132)$ returned their written responses directly to the researcher as part of a larger study (see McMillan and O’Driscoll, 2004).

\section{Step 2: conceptual simplification}

The first group of content analysts simplified the inductive data by subdividing the raw responses (which contained multiple themes) into discrete concepts. Instructions were: 'Here are some definitions of workaholism. Please break every response into single concepts.' Each definition of workaholism was reduced to phrases where only one idea was expressed. 'Agreement' was defined to have occurred where all three analysts concurred. The analysts reached 45 per cent initial agreements and 100 per cent agreements after discussion, and produced 298 final statements.

\section{Step 3: thematic analysis}

The second group of analysts clustered the 298 statements into seven themes. Instructions were: 'Here are some statements about workaholics. Please read all the statements and create 5-7 categories that capture the main themes expressed in the statements.' They reached 100 per cent final agreement and produced five final categories: (a) obsessive personal style, (b) driven by internal reasons, (c) time spent working and thinking about work, (d) work-leisure balance, and (e) work-relationships balance. The group emphasized that the 'driven' category represented a positive, 
constructive aspect of workaholism, whereas the 'obsessive' category was intended to represent a less functional and ostensibly more negative aspect of workaholism.

\section{Step 4: cross-validation}

The third group of analysts matched the randomized list of statements generated by the first group $(n=298)$ with the categories generated by the second group $(n=5)$. Instructions were: 'Here are some statements about workaholics and some categories that they are likely to fit into. Please place each statement into the most suitable category.' After individually coding each statement, $(n=162$ unanimous categorizations) they met as a group to discuss their differing decisions ( $n=136$ categorizations) with the researcher present as a data recorder, where 100 per cent final agreement was reached ( $n=298$ categorizations). The most frequently used category of classification by the third analyst group was time spent working or thinking about work ( 39 per cent), followed by obsessive personal style (22 per cent), which together accounted for the majority of definitions (61 per cent; see Figure 4.2). The remaining categories were used substantially less frequently: work-relationships balance was used 16 per cent of the time, driven to work by internal positive reasons was used 14 per cent, and, lastly, work-leisure balance was used only 9 per cent of the time.

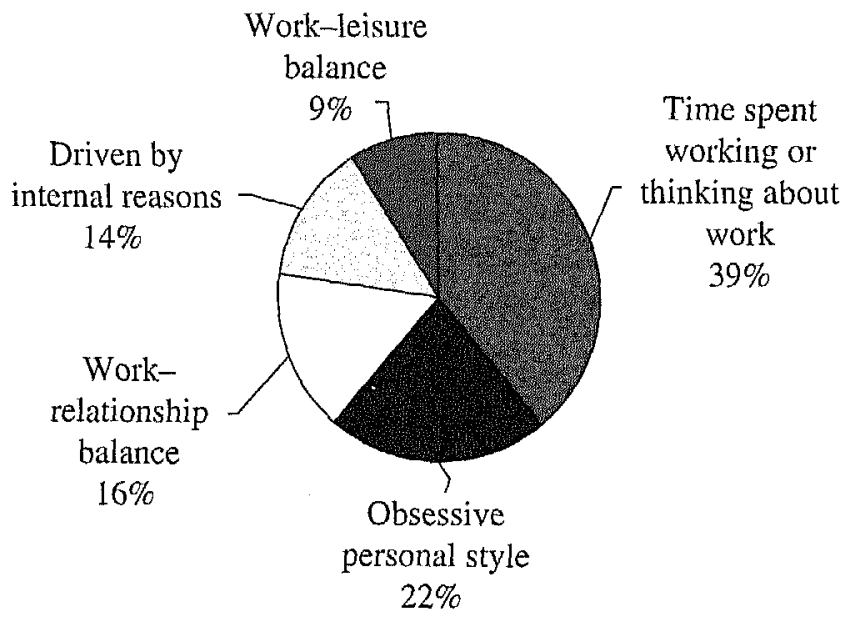

Figure 4.2 Pie chart depicting percentage of participants' statements categorized into each theme after cross-validation. 


\section{Results}

The final five categories proposed by the content analysts were: (a) obsessive personal style [that is, unable to stop, lack of control] (b) driven by internal (positive) reasons [such as passion, exceeding goals] (c) time spent working and thinking about work [that is, comparatively excessive], (d) work-leisure balance, and (e) work-relationships balance. In comparison, the theoretically derived (deductive) definition also comprised five aspects: (a) a personal reluctance to disengage from work, (b) a strong drive to work, (c) intense enjoyment of work, (d) a tendency to work or think about work, and (e) to do this any time and anywhere. These categories are presented in Table 4.2.

While much of contemporary workaholism research adopts the implicit assumption: Enjoyment + Drive $=$ Workaholism, the $(\mathrm{E}+\mathrm{D})$ category in the

\section{Table 4.2 Comparison of the deductive and inductive definitions of workaholism}

\begin{tabular}{|c|c|c|}
\hline $\begin{array}{l}\text { Category } \\
\text { number }\end{array}$ & $\begin{array}{l}\text { Inductive (empirical) } \\
\text { definition }\end{array}$ & $\begin{array}{l}\text { Deductive (theoretical) } \\
\text { definition }\end{array}$ \\
\hline 1 & $\begin{array}{l}\text { Obsessive personal style } \\
\text { [i.e. unable to stop, lack of } \\
\text { control, addicted, } \\
\text { can't help it] }\end{array}$ & $\begin{array}{l}\text { Personal reluctance to } \\
\text { disengage from work }\end{array}$ \\
\hline 2 & $\begin{array}{l}\text { Driven by internal } \\
\text { (positive) reasons } \\
\text { [e.g. passion, satisfaction, } \\
\text { focus, task orientations, } \\
\text { developing competencies, }\end{array}$ & Driven to work \\
\hline 3 & exceeding goals] & High enjoyment in work \\
\hline 4 & $\begin{array}{l}\text { Time spent working or } \\
\text { thinking about work [i.e. } \\
\text { comparatively excessive, } \\
\text { in terms of quantity and } \\
\text { quality] }\end{array}$ & $\begin{array}{l}\text { Tendency to work or think } \\
\text { about work }\end{array}$ \\
\hline 5 & $\begin{array}{l}\text { Work-leisure balance [i.e. } \\
\text { chooses work over } \\
\text { leisure time] } \\
\text { Work-relationships balance } \\
\text { [i.e. unclear boundaries } \\
\text { between home life/ } \\
\text { relationships and work life] }\end{array}$ & $\begin{array}{l}\text { Tendency to work any } \\
\text { time, anywhere }\end{array}$ \\
\hline
\end{tabular}


inductive data accounted for only one seventh (14 per cent) of the participants' definitions. In fact, the lay conceptualization suggests that workaholism comprises predominantly hours worked and thinking/talking about work (these elements accounted for 39 per cent of their definition). Thus it appears that a sizeable proportion of workaholism remained unexplained by combining $(E+D)$. Patently, we do not have clear evidence that a simplistic summing of enjoyment and drive fully accounts for workaholism.

\section{Discussion of Data}

The inductively generated definitions provided by participants hold some interesting implications for workaholism research. Firstly, as outlined in Table 4.2, the five inductively generated categories share considerable conceptual overlap with the five deductively generated (theoretically based) categories. For instance, there are parallels between both statements in category one, which concern difficulty disengaging from work and an obsessive personal style that includes being unable to stop. There are also direct overlaps between both statements in category four, which concern a tendency to work or think about work, and time spent working or thinking about work. Both statements in category five (working any time, anywhere, and an imbalance in leisure and relationships) also share a common theme, although it is important to note that the content analysis differentiated between leisure and relationships (see Table 4.2).

It is interesting, however, that two of the separate theoretical components of workaholism (Drive and Enjoyment) have been collapsed into one category in the inductive definition (see Table 4.2). This is not a new concept; Perez-Prada (1996) argued that the drive items of the (original) WorkBAT were confounded with enjoyment themes. For instance, the item 'It is important to me to work hard, even when I do not enjoy what I am doing' appeared to tap both constructs. This provides an interesting hypothesis for future research.

Importantly, both the inductively generated (that is, qualitative) and deductively generated (that is, quantitative) definitions are consistent with the majority of existing theoretical literature. Firstly, neither data set includes disturbances in health, happiness and relationships, as suggested by Oates (1968). However, both definitions specify the structure and magnitude of workaholism. In particular, the present definitions encompass the desire to work long and hard, as noted by Machlowitz (1980), and the excessive involvement in work noted by Porter (1996). However, both definitions are relatively operational as they specify how to generate the dependent variable (workaholism). The data also gave qualified support to the Scott et al. (1997) definition that included (a) discretionary time spent 
working, (b) thinking about work when not at work, and (c) working beyond requirements, and Snir and Harpaz's (2004) definition involving time allocated to work activities and work thoughts. Overall, the present quantitative-qualitative definitions integrate and link several of the themes in the literature and, on this basis, provide an important foundation from which to conduct further research.

\section{CONCLUSIONS: PRELIMINARY CONCEPTUAL MODEL}

The apparent failings of contemporary research designs to substantiate the $(\mathrm{E}+\mathrm{D})$ proposition as the sole explanatory factor in workaholism prompt such questions as 'What is workaholism?' and challenge the notion that it is a unitary phenomenon. Perhaps, as Mudrack and Naughton (2001) suggested, the tendency to work or think about work is actually the essence of workaholism, while Enjoyment and Drive are merely antecedents that trigger the workaholic behaviour. Although Spence and Robbins' (1992) Work Involvement factor has repeatedly performed poorly in terms of psychometric qualities (it yields low internal consistency and is often saturated into the other two variables), it may capture some of this time-related aspect of workaholism. Clearly, our understanding of the antecedents and components of workaholism could benefit from further empirical enquiry. It is certainly feasible that Enjoyment and Drive are constructs that are related to workaholism, but whether they merely describe workaholic behaviour, as opposed to explaining its origins and causes, remains unknown. Therefore, it is feasible that Enjoyment and Drive are antecedents that trigger a repertoire of workaholic behaviours that consist of working, thinking and talking about work, striving for achievement and demonstrating a strong work ethic.

This raises the contention that perhaps researchers should abandon the unitary workaholism construct, much as they have done with Type A, and focus instead on studying enjoyment, drive and hours worked as separate constructs, albeit inter-related. In any event, it is apparent that the nature of workaholism remains unclear and further research is required to determine (a) whether the construct is unitary or multifaceted, (b) whether it has utility, and (c) whether it merely describes a set of behaviours that are triggered by the independent constructs of Enjoyment and Drive. Thus, workaholism may represent an abstract concept that acts as an umbrella for specific variables, rather than being a variable or construct in its own right. If this is the case, logic dictates that future research should explore Drive, Enjoyment, hours worked and hours thinking about work as specific 
manifestations of this umbrella concept, rather than subsuming them under one label.

It is conceivable that drive and an obsessive personal style are antecedent traits that interact with and are reinforced by enjoyment to produce workaholic behaviour that involves a tendency to work or think about work incessantly. This behaviour produces consequences that include working any time, anywhere. In turn, these consequences are likely to provide discriminative stimuli for further working. These propositions are modelled in Figure 4.3, which, it must be reiterated, is very tentative and intended to spur further research questions, rather than provide definitive answers about the nature of workaholism. Clearly, further testing is required to examine these propositions.

The working model yields several other potential hypotheses. For instance, the model implies that certain personality traits (such as Obsessiveness) precede workaholism. Furthermore, the reluctance to disengage from work is implied, but has not actually been measured - for instance, research taken 'at the point of disengaging from work' could elucidate the subtleties of this process. Does the person attempt to disengage

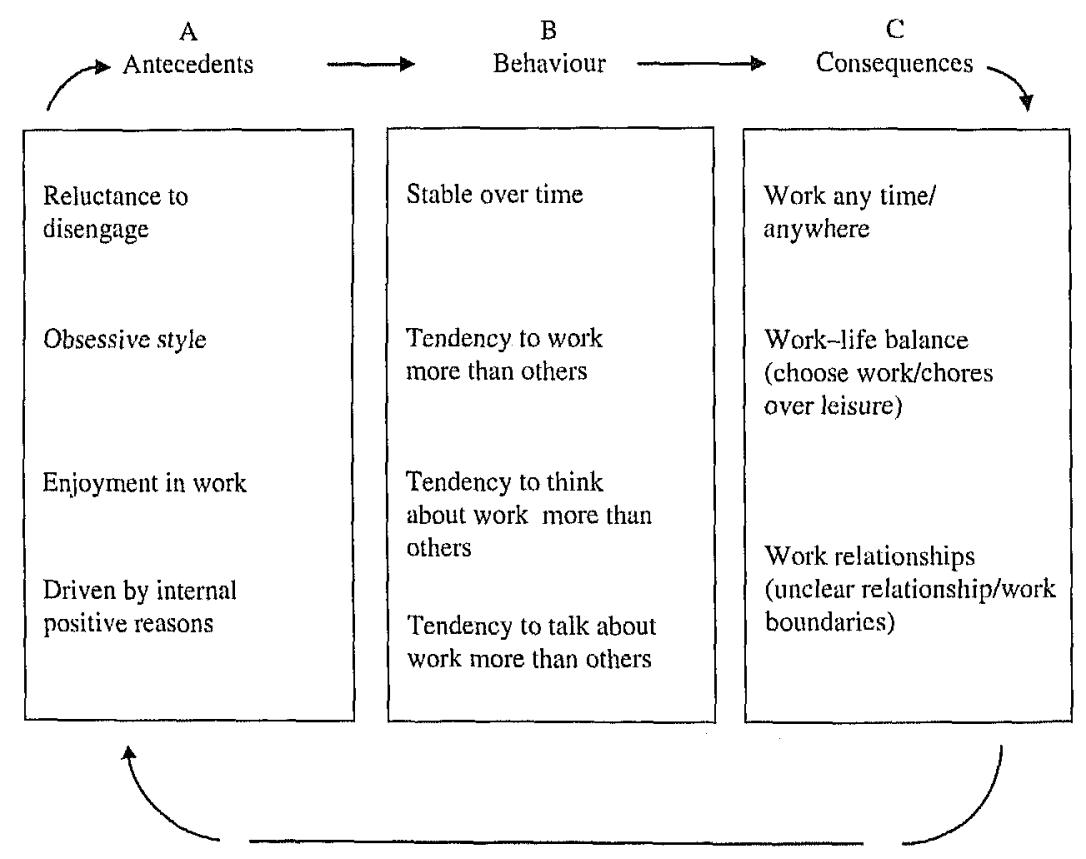

Figure 4.3 An integrated model of workaholism based on inductive-deductive data 
several times before they succeed? Do they use certain cognitive tactics to help themselves disengage from work each day? Specifically, further theoretical development, hypothesis testing and structural equation modelling are required to ascertain the scientific and applied utility of this tentative model.

\section{SUMMARY}

Overall, the majority of workaholism data and definitions are quantitatively based and rooted in positivist, deductive paradigms. While some encouraging qualitative work has been published, it is largely anecdotal and remains untested by either scientific frameworks or peer review processes. The present comparison of an inductively and a deductively generated definition illustrates that both academics and the general public view workaholism in similar terms, involving (a) reluctance to disengage [obsessive style] (b) a strong drive to work [driven by positive reasons] (c) enjoyment in work, (d) a tendency to work or think about work [time spent working and thinking about work] that (d) occurs any time and anywhere [work-leisure and work-relationships balance]. This raises the interesting possibility that workaholism represents an approach to work, (that is, intensity of working), as opposed to a frequency, and may be observed as a qualitative characteristic that distinguishes workaholics from other workers.

As the present chapter has demonstrated, integrating both deductive/ positivist and inductive/post-modernist epistemologies may provide substantial insight into the nature of, and mechanisms underlying, workaholism. Given that research on this construct has been conducted for four decades now, it is timely to leave behind the simplistic pen and paper studies and adopt more sophisticated research methodologies such as triangulated data sources, composite qualitatitive-quantitative designs, and epistemologies that elucidate the factors that perpetuate and maintain workaholism.

\section{REFERENCES}

Berg, B.L. (1995), Qualitatitive Research Methods for the Social Sciences, 2nd edn., Needham Heights, MA, USA: Allyn and Bacon.

Burke, R.J. (1999), 'Workaholism among women managers: work and life satisfactions and psychological well-being', Equal Opportunities International, 18 (7), 25-35.

Campbell, D.T. and Fiske, D.W. (1959), "Convergent and discriminant validation by the multivariate-multimethod matrix', Psychological Bulletin, 56, 81-105. 
Clark, L.A., Livesley, W.J., Schroeder, M.L. and Irish, S.L. (1996), 'Convergence of two systems for assessing specific traits of personality disorder', Psychological Assessment, 8, 294-303.

Clark, L.A., McEwen, J.L., Collard, L.M. and Hickok, L.G. (1993), 'Symptoms and traits of personality disorder: two new methods in their assessment', Psychological Assessment, 5, 81-91.

Fassel, D. (1992), Working Oursetves to Death, London: HarperCollins.

Ivancevich, J.M. and Matteson, M.T. (1988), Application of the triangulation strategy to stress research', in J.J. Hurrell, L.R. Murphy, S.L. Sauter and C.L. Cooper (eds), Issues and Developments in Research, New York: Taylor and Francis, pp. 200-215.

Machlowitz, M.M. (1980), Workaholics: Living with Them, Working with Them, Reading, MA, US: Addison-Wesley.

McMillan, L.H.W. and O'Driscoll, M.P. (2004), 'Workaholism and health: implications for organisations', Journal of Organizational Change Management, 17 (5), 509-19.

McMillan, L.H.W., O'Driscoll, M.P. and Brady, E.C. (2004), 'The impact of workaholism on personal relationships', British Journal of Guidance and Counselling, 32 (2), 171-86.

McMillan, L.H.W., O'Driscoll, M.P. and Burke, R. (2003), 'Workaholism: a review of theory, research and future directions', in C.L. Cooper and I.T. Robertson (eds), International Review of Industrial and Organizational Psychology, 18, 207-30, NY: John Wiley and Sons.

McMillan, L.H.W., O'Driscoll, M.P., Marsh, N.V. and Brady, E.C. (2001), 'Understanding workaholism: data synthesis, theoretical critique and future design strategies', International Journal of Stress Management, 8 (2), 69-91.

McMillan, L.H.W., Brady, E.C., O'Driscoll, M.P. and Marsh, N.V. (2002), 'A multifaceted validation study of Spence and Robbins' (1992) Workaholism Battery', Journal of Occupational and Organizational Psychology, 75, 357-68.

Mudrack, P.E. (2004), 'Job involvement, obsessive-compulsive personality traits, and workaholic behavioural tendencies', Journal of Organizational Change Management, 17 (5), 490-508.

Mudrack, P.E. and Naughton, T.J. (2001), 'The assessment of workaholism as behavioral tendencies: scale development and preliminary enpirical testing', International Journal of Stress Management, 8 (2), 93-111.

Oates, W.E. (1968), 'On being a "workaholic" (a serious jest)', Pastoral Psychology, 19. $16-20$.

Perez-Prada, E. (1996), 'Personality at work', unpublished doctoral dissertation, Saint Louis University. USA.

Porter, G. (1996), 'Organizational impact of workaholism: suggestions for researching the negative outcomes of excessive work', Joumal of Occupational Health Psychology, 1, 70-84.

Robinson, B.E. (1989), Work Addiction: Hidden Legacies of Adult Children, Florida, US: Health Communications.

Robinson, B.E. (1998), Chained to the Desk: A Guidebook for. Workaholics, their Parthers and Children and the Clinicians who Treat them, New York: New York University Press.

Robinson, B.E., Flowers, C. and Carroll, J. (2001), 'Work stress and marriage: a theoretical model examining the relationship between workaholism and marital cohesion', International Journal of Stress Management, 8 (2), 165-75. 
Scott, K.S., Moore, K.S. and Miceli, M.P. (1997), An exploration of the meaning and consequences of workaholism', Human Relations, 50, 287-314.

Snir, R. and Harpaz, I. (2004), 'Attitudinal and demographic antecedents of workaholism', Joumal of Organizational Change Management, 17 (5), 520-36.

Spence, J.T. and Robbins, A.S. (1992), 'Workaholism: definition, measurement, and preliminary results', Journal of Personality Assessment, 58, 160-78. 